\title{
Metallurgy and Material Science an Detailed Analysis
}

\author{
${ }^{1}$ Sudha $\mathbf{J}$ and ${ }^{2}$ Ramya K \\ 1,2 Research Scholars, Department of Mechanical Engineering, Anna University, TamilNadu, India. \\ ${ }^{1}$ sudhaj9825@gmail.com, ${ }^{2}$ ramyak@annauniv.edu
}

\author{
ArticleInfo \\ Journal of Machine and Computing (http://anapub.co.ke/journals/jmc/jmc.html) \\ Doi : https://doi.org/10.53759/7669/jmc202101013 \\ Received 10 March 2021; Revised form 20 April 2021; Accepted 02 June 2021; Available online 05 July 2021. \\ (C)2021 The Authors. Published by AnaPub Publications.
}

This is an open access article under the CC BY-NC-ND license. (http://creativecommons.org/licenses/by-nc-nd/4.0/)

\begin{abstract}
In the history of metallurgy, Gold, cleaned from metal ores and melted, was the first metal used by humans. During the advent of civilization, copper was introduced through the reduction process of oxides in traditional furnace. This process was considered the first chemical process of producing metals, and this was used in $4000 \mathrm{BC}$. Nonetheless, this process was gradually superseded by bronze i.e. alloy of copper with $10 \%$ tin, which is easier to cast and melt. Bronze was obtained through the mixture of tine retrieved from its oxides during the process of reduction or from the reduction of copper mixtures and tin ores. This age of civilization, i.e. $2400 \mathrm{BC}$ was known as the Bronze age. With that regard, this paper focuses on the history of metallurgy with major focus on particular metals i.e. copper, iron and gold. In addition, this paper evaluates the contributions of scientists to the field of metallurgy.
\end{abstract}

Keywords - Metallurgy, Gold, Iron, Copper, Metal Ores.

\section{INTRODUCTION}

To evaluate advent of metallurgy, it is fundamental to consider particular methods used, on a daily basis, in lithic communities. This is because the use and application of metals was evident from lithic humans with knowledge about material science and metallic materials. The applications of red oxides of irons are funerary and ritual practices, which were well known during the earliest times. Neolithic individuals had also decorated their walls using this metal and at Susa and Eridu pieces of the hemaite were utilized for the gleaming pottery by approximately $4000 \mathrm{BC}$. The blues and greens of copper materials would particularly appear and their applications for cosmetics were applied in Mesopotamia and Egypt. Minor azurite pieces were discovered in Crete, in their habitational layers in 6000 BC [1].

It did reach the Neolithic period when green minerals were still in use for the decoration of pottery; their unpredictability could be evident soon for the red oxide of irons, copper-centered minerals turning dark in color when heater under oxidized environments [2]. The influence of minimizing conditions in generating globules of metallic leads during lead glaze firing is considerably known during the period. It might be wondered if the process of smelting could be done in this manner. However, there is no existing evidence regarding this process, but encrypted kilns, where minimizing conditions could be applicable, we did not know this until the Copper Age [3]. This was the period that showed that success incidents were due to the advent of copper smelting Glaze was considered before glass, while soapstone (glazed steatites) were considered from one of the earlier times in Egypt, during the Badarian period i.e. 5000 $\mathrm{BC}$. However, there is still no evidence for the use and application of copper in a glaze. Copper has been identified in the glaze quartz-frit considered as faience, and this was not later that the $18^{\text {th }}$ dynasty. Clay tablets incorporating dual recipes for the green glaze was identified in Tigris, in 1600 BC. All these recipes incorporated significant components of copper.

In the middle age, alchemists thought that they could transform the baseline of metals such as iron into gold, i.e. metal transmutation; but this was not easier. In metallurgy, not significant activity happened during the Dark age of magic, alchemy and superstition other than salts and acids preparation and description. The introduction of metallic zinc was considered in $1200 \mathrm{AD}$ [4]. Novel metals, which are similar to tin, were generated through heating of calamine with organic materials in crucible fits that have been covered with condensed zinc vapor found in refractory crucibles.

In the late 1370s, Indians had identified that zinc was a novel metal, number eight to be introduced to humans. However, during that time, limited amount of the metal, for commercial purposes, was produced. During the $13^{\text {th }}-14^{\text {th }}$ century, three novel metals (bismuth, antimony and arsenic) gained popularity in Europe in its elementary condition. The art and science of extracting metals began to take its shape during the translation of Arabic writings to Latin and during the knowledge flow (chemical knowledge) to Europe with respect to Italian Renaissance. From Indian, the production and manufacturing of zinc shifted to the Chinese around $1600 \mathrm{AD}$. China developed industries to the supply needs of brass production and manufacturing. The production of Zinc became popular in Europe after its origin in China approximately half a century later. China also initiated a preparation of other alloys that were similar to silver; 
but incorporated copper instead i.e. paithung, which is white copper. This metal alloy was transported to Europe in smaller amounts during the early 1700s. Later on, it was noted that the alloy incorporated a novel metal i.e. Nickel.

In the $18^{\text {th }}$ century, analysts, travelers and mineralogists initiated the advent of novel metals. The specimens of metals from various localities were constantly supplier into the labs where they were evaluated critically. Resultantly, thirteen novel metals were introduced i.e. chromium, beryllium, yttrium, titanium, zirconium, uranium, tungsten, tellurium, molybdenum, manganese, nickel, platinum and cobalt. During the period, a high need to educate students for metallurgy, metal extraction, and mining and geology skills was fundamental and this amounted to the establishment of institutions in Europe including Spanish colonies where significant mineral activities existed. Other significant activities amounted to the comprehension of the smelting process and conditions of fire. It was considered that during the burning process of coal, phlogiston was emitted and calx remained.

In the $19^{\text {th }}$ century, many metals were introduced. The timeline for their introduction was due to preceding introductions. During the start of the century, electric current was discovered and this was a fundamental resource in metallurgy. The novel Volta cells were utilized for the first time (by a chemist and scientist Humphry Davy) to introduce novel metals. The chemist interlinked larger amounts of cells in a series and therefore was capable of generating massive current. The scientist also considered the decomposition of aqueous potash that generating oxygen and hydrogen. In the later times during the same century, Davy focused on solid potash, which incorporated moisturized conduction of current. In this manner, it was noted that something was able to burn luminously at the cathode. This was named Potassium and it was considered significantly reactive when burnt in air. In similar way, Davy conducted an electrolysis of soda ash and showed that sodium metal can effectively be liberated.

In the $20^{\text {th }}$ century, lutetium, promethium and europium were introduced. Moreover, two novel radioactive metals ie francium and protactinium, were introduced. Following the advent of the spectroscope leading to the introduction of four metals in the $19^{\text {th }}$ century, the analysis of spectrum x-ray by Moseley Henry in the early 1910s amounted to the introduction of two novel metals in the $20^{\text {th }}$ century i.e. rhenium and hafnium. In the same way, the advent of cyclotron was obliged the advent of novel metal: technetium and the elements of transuranium. Briefly, after the advent of the process fission of uranium in the later 1930s, the possibilities of harnessing atomic power was recognized.

To attain this objective, metallic uranium would be needed on a massive scale. Because no larger deposits of the metals were identified during that time, low-quality metal ores have to be produced. This led to massive scale use of solvent extraction and ion exchange in the field of metallurgy. In addition, the requirement for metals with special features for their application in nuclear reactions amounted to sudden interests in earlier rarely applied metals e.g. thorium, potassium, sodium, cadmium, zirconium and beryllium. Therefore, novel techniques for extraction were introduced on a massive scale for instance, fused salt electrolysis, fluorination and chlorination.

Section II has presented the history of metallurgy considering the metals that were introduced up to the $20^{\text {th }}$ century. The remaining part of the paper will focus on three metals i.e. copper, iron and gold. This paper will also add and assess the contributions of scientists in the field of material science and metallurgy. In that regard, the remaining part of the paper is organized as follows: Section II presents a literature survey of this research. Section III presents a critical analysis of the paper, with major focus on copper, iron and gold. In addition, the section focuses on the relevant contributions of scientists in the field of metallurgy. Lastly, Section IV concludes the paper.

\section{LITERATURE SURVEY}

In [5] evaluated the Bronze Age, which was accustomed by archaeologists as the first metal age. This was the period that was earlier considered as the copper artefact i.e. copper and tin alloys. Nonetheless, it is presently considered that it took more time for the actual Bronze age to come and research indicate that before this Bronze was considered a metal, there was a longer period when copper smelting of significantly pure coppers of antimony and arsenic were utilized. In most parts of the globe, there was confusion between true bronze and other metals during the British Wessex Period.

In [6] evaluated the non-tin bearing copper. It was typically challenging to conclude when a particular culture started. According to the works of archaeologists, terms such as Eneolithic and Chalcolithic were defined similarly and represented a period of change between the Copper Age and the Neolithic period. Is the first appearance of the copper metal marking the start of the Copper Age? This query has already been answered, as negative and copper smelting is presently our major focus. Nonetheless, what is the extent of use and application for a material to have an age identified after it?

The Authors [7] argues that there were longer copper periods when the metal was comparing itself with stones and flints. During the advent of more deposits of copper and the introduction of methods of extractive metallurgy in the lithic community, the differentiation between Copper Age and Chalcolithic is a major factor to consider. Since tine has been conferred on copper cast components, more strength in case-state without requiring cold operations, was indeed a significant invention. However, this ideal was developed in a gradual manner and in the East, there is a period when tin and arsenic were combined.

The [8] evaluate the countries that divided Bronze into late, middle and early periods with respect to metallurgy. However, this is considered an exception instead of a protocol. According to British Isle, metals utilized during the earlier periods were standard tines and arsenic copper with an exception of lead and arsenic.

In [9] evaluated the Middle Bronze Age where alloys were used as standard tine bronze that were more than $99 \% \mathrm{Su}$. During the late periods of the same age, alloys typically incorporated $9.5 \% \mathrm{Su}$. However, lead was considered into the process of casting. The advent of lead was not considered global, and Britain seemed to suffer limitations than the southeastern sides. In other nations, the metal was normally identified in bronze. It is thus more effective to subdivide the period into full Bronze Age, experimental age and earlier age. It is appealing that the Iron Age began in minor parts of Asia where humans using iron occupied the part during $200 \mathrm{BC}$. 
The [10] commented that during the Bronze Age, the copper metal ore could be smelted using iron flux with more differential possibilities of iron metal being minimized in fires. This would have amounted to fire bottoms to incorporate ductile iron and slag according to more recent smelters of coppers in Iran. This range of possibility would have occurred in LBA and there no existing explanation why Asia minor people would have used it in the first place if they were not acquitted with the smelting of copper.

In [11] reviewed the occasional literatures regarding iron in the earlier times. However, metallic pieces were considered single artefacts and meteoric artefacts, which might be disregarded in this case or amounted to accidents. One case is the Pyramid of Cizeh plate, which had been stratified effectively. Particularly, its structure and composition was not normal to the wrought irons that had fayalite slags and stringer. There is no evidence regarding the person who made iron in quantity and intentionally. It could be at Anatolia where there were the first daggers of irons.

The [12] argue that the distribution of manmade irons during the $\mathrm{BC}$ second millennium was spasmodic and minor. However, it slowly developed until it was utilized on a massive scale to produce weapons in 1000 Be. The gradual introduction of irons was a repetitive process while in the Iron Age, and bronze, for a long time, was meant to cater for numerous metallic applications. Due to its rarity, the metal was firstly utilized in minor jewellery items. Other than this, its earlier application seemed to be blade daggers.

In [13] considered leaded bronze and cast in bronze to be less ductile with the capacity to endure critical blow without any form of breakage; and might have significant demerit. Whenever iron blades were introduced, the merits would be evident with an immediate effect. Bending swords could be uncurled; however, a breakable sword is less significant. The [14] evaluated the production of bronze hilted iron blade by Smiths Luristan in the $11^{\text {th }}$ century. The blade was considered hard and significantly ductile compared to the cast-tin bronzes. Luristan hilts ironic swords were more traditional, and it is evident that interlinking dissimilar irons for hilt fabrication was a critical issue to Smiths.

Many researchers argued that this similar issue is evident in the interlinkage for making miniature headrests identified in the tomb of Tutankhamun's. Smiths could make fewer amounts of irons, and these were linked to other pieces without effective processes of welding and deformation. It can be noted that iron was starting to be available in larger quantities by the $8^{\text {th }}$ century. At Khorsabad in the Palace of Sargon II, iron was found in double form pointed square bars. This tribute was from a wider part of the Assyrian Kingdom and lasted five centuries later when scientists utilized different bars of different forms in the drafting of commerce literatures.

In [15] evaluated native metals such as platinum and gold. Gold is existing in its primitive metallic forms. Nonetheless, unless it is obtained as nuggets, it is challenging to utilize it in its native form, as a fine particle that is dust-like, gathered by washing in bed streams. Although nuggets are still not obtained on surfaces in the modern age, they were seen during the primitive ages. Nugget composition is typically the same as the materials mined deeply in the ground and their there is not present form of distinguishing deep-mined gold and primitive nuggets.

Section III below narrows down the paper to an evaluation of three metals: copper, iron and gold. This section also proceeds to an assessment of contributions from scientists in the field of metallurgy and material science.

\section{Copper, Iron and Gold}

\section{CRITICAL ANALYSIS}

\section{Copper}

The availability of primitive coppers and meteoric irons have been known for ages; however, the channel of identifying native coppers is somehow more than dimensions to which it is generally realized All the small and large copper deposits generate quota of primitive coppers. Minor objects of copper e.g. awls, pins, beads turned up intermittently during the $19^{\text {th }}$ century e.g. in Ali Kosh, Iran. It is challenging to distinguish between the smelted copper from clear ores and melted native coppers, but only if the primitive copper has not been melted, differentiating it is applicable.

Primitive coppers were once considered to be cleaner compared to the coppers provided from the cleaner ores. Literature works completed over the past few decades indicated that this differentiation is considerably dubious. Various assessments have been completed and the most recent assessments of native metals of considerably lower purity have been done. This major issue with primitive coppers is its considerable heterogeneity. A number of pieces comprise of significantly larger grains; however, some are minor angular crystals that have massive deposits and cavities of gangue (unwanted mineral e.g. calcite) in its interstice.

Due to this reason, the components such as silicon, magnesium, aluminium and calcium have been eliminated from the assessments mentioned above since it is certain they are known for their impurities. Micro-assessments also indicate the availability of irregular parts that etch different from masses and it is considered that these are correspondent to smaller variations in composition, certainly of silver and arsenic. The content of silver of $0.042,0.052$ and 0.0116 has been considered to bear the same lump whereas silver is considered to attain significantly higher values as $0.6 \%$.

Gold is typically absent or undetected. Arsenic, iron, antimony, lead and nickel are considerably rare. The last four incorporate the major diagnostic components following the advent of primitive metallic artefacts. It is considered that the features of native coppers significantly reflect the deposits in its occurrence. Primitive copper nodules retrieved from Maden Ergani smelters of the late 1960s were $1.45 \mathrm{~kg}$ and comprised of twelve zones. Every zone comprised of crystalline aggregated; some indicating a twinning sign. The electronic probe assessment indicted that copper incorporated considerably Fe and Sulphur.

Gangue stage between different zones was significantly titaniferous with respect to silica and iron oxides. However, $\mathrm{Sb}$ was not available. The differentiation with Iranian coppers from Anarak and Talmessi that incorporated about $15 \%$ is lower in all of them but about 0.15 in Ag. It is vivid that impurities in primitive coppers can be segregated and the real assessment done will be based on the technique used. Wide-range primitive copper is significantly pure compared 
to many ores of significantly lower degrees. In that case, it is considered that when a purse artefact is identified in its earlier context, it is probably that it originates from primitive copper.

In case an artefact has been structured from hammered primitive coppers, as long as it is not heated above a particular temperature, some features of primitive coppers will be seen. In annealing, grain boundary impurities are considered appealing in fixing the boundaries of grain and a soluble segregate is not diffusible until when the temperatures are $599^{\circ} \mathrm{C}$ and above. It should not be doubted that the content of silver is fundamental obliged for the raise of recrystallized temperatures of primitive coppers that are invariably identified in operational state, and the stiffness varies from $60 \mathrm{HV}$ to $100 \mathrm{HV}$ on a Vicker scale.

Assessments have proved that primitive coppers cannot be operated without intermediate annealing. A lot depends on the overall sizes of the initial grain and the chances of cracking are spread over the boundaries of the grain. It has been proved that, since the incipient crack is eliminated during the process of forging, Iranian coppers and pieces in Michigan can be minimized by approximately $95 \%$ and therefore it is possible to provide heads and minor axe heads. Smaller copper heads from Iran during the $7^{\text {th }}$ century were assessed and identified to have structured rolled-up sheets of coppers of approximately $0.4 \mathrm{~mm}$ in thickness. Its polygonal shapes were similar to the ones produced by experimentation and there are minimal doubts that it was structured from primitive coppers.

Pinning from the northern mound (at Sialk) was also assessed and this was more effective in its condition and dated back in the $5^{\text {th }}$ millennium Be. Microstructures indicated that it is significantly operated primitive copper, which is similar to the novel worked coppers from Iran. The chemical characteristic was the same and its stiffness was about 110 HV. Normal objects indubitably structured from primitive coppers are awl from Iraq and Magzallia. This was considered as a high-quality copper with purity of $0.25 \% \mathrm{Ag}$ whereas some were segregated.

It is significantly corroded and the components in residual metallic cores were Bi- $0.00015, \mathrm{Fe}-0.02, \mathrm{~Pb}-0.012, \mathrm{Ni}$ $0.0015, \mathrm{Zn}-0.085$ and Sn-0.0085. Their micro-hardness was $105 \mathrm{HV}$ that also incorporated their structures and showed an influence in severe cold works. As in the $7^{\text {th }}$ millennium, these were the oldest pieces of worked primitive coppers identified. When primitive coppers were being melted, gangue elements were separated and left floating. The segregates that were soluble dissolved and the metals were considered homogeneous with normal cast cored in structure and with minimal stiffness. In one instance, the stiffness was minimized from $85 \mathrm{HV}$ to $35 \mathrm{HV}$.

Our knowledge about primitive copper artefact originates from the modern world. Critically crafted components were structured in larger quantities from primitive coppers that have not been melted in regions of Lake Superior, America in $2900 \mathrm{BC}$. The spearhead was for the ancient copper cultures during $2900 \mathrm{BC}$. In some instances, it was tanged (designated to shafts) while others to the tang and considerably worked into half sockets. All indicate massive hardening work with mean stiffness of artefacts varying from $58 \mathrm{HV}$ to $107 \mathrm{HV}$.

Since the witnessed structured were the annealed materials incorporating cold works, it was considered that normal processes were to anneal and hammer coppers until the last shapes were closely obtains, and then the finish objects obtained using localization or cold working. In some instances, they were left in completely annealed situations. This indicates that lithic civilization was capable of going one-step higher those typically hammering primitive coppers. The civilization applied knowledge, which showed that furnace heating made it softer to facilitate more work. Even though annealing temperatures were normally higher, i.e. more than $790^{\circ} \mathrm{C}$, there were no processes of melting to attained points e.g. $1080^{\circ} \mathrm{C}$. Hence, forceful draughts were fundamental.

\section{Iron}

The meteoric irons were present during the lithic times. These were typically contain approximately $9 \% \mathrm{Ni}$ and were therefore stiffer and much more challenging to operate on. The content of nickel was from $5 \%$ to $25 \%$ and could be identified with ease since there were limited ores with the capacity to give this degree of Nickel in its homogeneous state when directly smelted. It was evaluated that there were about 220 extents of meteoric materials, and that $99 \%$ are malleable. Nonetheless, the issues are similar like the ones reported in primitive coppers. When hammered coldly, materials crack alongside a well-structured crystal plane. With annealing and hot forging, minor artefacts can be structured and lithic community in Greenland was capable of making tools out of the meteoric materials with approximately $7 \% \mathrm{Ni}$. Whereas prolonged treatment of heat at higher temperatures tends to destroy meteoric structures of irons, the materials will be able to identified using decomposition.

Another iron source is the telluric irons. Minor grains are available in basalt and are significant enough to forge into a flake that can be incorporate in the organic hilts for knife manufacturing with serrated edges. These grains basely have more than 4\% nickel. Greenland has presented some samples of telluric and meteoric irons. The major source of the latter is the meteorite from Cape York that was emitted in the atmosphere and produced 7.5\% nickel in scattered form. Some meteorite pieces and some Eskimo tools structured out of it were found in Scandinavian gatherings and Mosdal and Buchwald have assessed some. A number of them have been operated coldly; but none of them has been hot operated. This is due to the deficiency in fuels for hot operations.

The degree of stiffness is about $199 \mathrm{HV}$ for the 'unoperated meteorite' to $329 \mathrm{HV}$ for the coldly forged blade. Annealing minimizes the stiffness degree to $154 \mathrm{HV}$. Vividly, the initial materials would be strained before touching the earth. There are no challenges minimizing the thickness to approximately $90 \%$ of initial with $2 \mathrm{~kg}$ steel hammers. Telluric irons occur on Disko off the coast of Greenland in two types. The first one, a malleable type, incorporates a mean of about $0.4 \%$ to $2 \% \mathrm{Ni}$ and $0.15 \% \mathrm{C}$ and $1.1 \% \mathrm{C}$. Other non-malleable white casts' irons incorporate $2 \% \mathrm{Ni}$ and $1 \%$ to $5 \% \mathrm{C}$. Maximum content of nickel is significantly lower for meteoric irons and carbon significantly higher.

The first one happens as smaller grains of $1 \mathrm{~mm}$ to $5 \mathrm{~mm}$ in diameter. The second one is based on the fragmentation of hammering; however, it could seem to happen on large portions of basalt boulders. The most recent type indicates not just the usage of meteoric irons but also its identifiable characters, irrespective of its period of mineralization after a 
period of 3000 years. This is found in the dynasty of the bronze age of Shang the Chinese. Smaller segments of meteoric irons had been utilized to enhance the cutting edges and the featured alpha and gamma widmanstatten features were noted when applying electron probes, as higher $\mathrm{Ni}$ and lower $\mathrm{Ni}$ lamellae, which are available in the rusts.

Vividly, minimal Ni diffusion had happened; however, some general loss must have happened, as one might not project any piece of meteoric irons to have this kind of lower Ni content i.e. 1.8\%. Bronze penetration in the iron cracks indicate that a was constructed by bronze casing on blades of irons incorporated in the moulds. Some iron objects have been identified in pre-ironic ages and most of them that have been assessed have nickel. However, some have been reported to have no nickel content hence creating some issues. One of issues under concern is that they might have gotten into earlier accidents or the might have been dated wrongly in case they are found in Bronze or Copper ages. If this is the case, they might have resulted from the process of smelting under these conditions that irons have been minimized from the slags and fluxes of ferruginous smelting of coppers.

One of the pieces has been identified in Gizeh and date to the $3^{\text {rd }}$ millennium BC. It is particularly not the meteoric and incorporate reduced portions of iron oxide that have been hammered together without slags available in wrought irons. It would be considered that some of the smiths were able to make operative non-meteoric irons. These meteoric irons were particularly utilized without knowledge into earlier ironic ages and even in the later periods. The socketed iron axe-head, which dates in $8000 \mathrm{BC}$ was considered to bear an average content of nickel of about $5 \%$.

The content of nickel was because of lamination that incorporated $10 \% \mathrm{Ni}$ in the middle of axe-head. This was in the range of meteoric irons. Smiths of these times normally welded the iron pieces of various origins and it might seem that a single portion of these pieces had originated from meteoric irons. Nonetheless, it is applicable for thinner layers of higher contents of nickel to be obtained in the wrought irons by enriching the surface with nickel during the process of oxidation when preheated for falsifying. Higher nickel lamination can be brought by pilling i.e. through bending over, welding and hammering of same pieces repeatedly.

\section{Gold}

Gold is one of the native metals. Gold occurs in its primitive metallic type. Nonetheless, unless it has been identified in its nugget form, it is challenging to utilize it in its primitive form, as finer particle, which are in form of dust available in stream beds are not seen easily and even not consolidated through the process of melting. Just like in the past, nuggets are found on surfaces today. The components of the nugget materials are normally similar at the deeply mined materials; in that case, it is challenging to distinguish primitive nugget materials and pure gold mined deeply. Natural gold is considerably impure, typically assaying approximately $8.5 \%$ silver and $1.5 \%$ copper. One assessment of some gold artefact in Europe indicated that there existed approximately two groups. One was the same as the gold that had speculated to originate from Wick low hills and other from a different origin, but not Irish.

However, further series of Hungarian and Romanian origins were identified the same way as the first group. There were minimal doubts that there were considerable variations in impure contents of primitive gold; nonetheless, no evidences show that this has any form of archaeological importance. To offset whitening aspect of silver in the natural gold, primitive communities had to master the art of adding copper. Primitive copper content, as seen from assessments by Eluere, it is less than $0.15 \%$. However, there are natural golds with higher values compared to the one adding to $1 \%$. Whenever the content of copper of artefacts is more than this, it is considerable that is has been incorporated with intent. It is factual that there are no gold artefacts that are date during the earlier time than the $5^{\text {th }}$ millennium $\mathrm{BC}$, and nuggets have to be identified due to their malleability utilized by lithic communities. It can only be conjectured that, for lithic communities, gold was considerably valuable and can be buried in the graves and pilfered into circulations. This shows that more $3^{\text {rd }}$ and $4^{\text {th }}$ millennium gold was re-applied materials.

Platinum, just like gold, appears in water borne grains available as alluvial gravel. This contain from $50 \% \mathrm{Pt}$ to $80 \%$ $\mathrm{Pt}$, the remaining portion incorporates the metals in the group of platinum with minor amounts of baseline metals. Many of the known occurrences were in S.A mostly in Ecuador and Colombia. Other sources were in Ural hills of USSR. Minor nuggets were about $36 \mathrm{~g}$ created the most recent coinages available in Russia. However, there are no evidences for purposeful application of platinum in this part in antiquity, even when it occurs as a typically inclusion in golden artefacts and must have influenced a greater deal of primitive gold operators.

It is unfortunate that the inclusion compositions in no way shows gold provenance. The elements incorporating larger amounts of platinum have been identified in S.A and minor pieces in Egypt. It is not consider, nonetheless, that primitive communities identified metals as a different entity. Alloys with silver, platinum and gold, in proportions of 11:18:70, were identified among earlier materials from parts such as Ecuador, which had been in Inca possessions and contents of platinum in objects structured by Indians during the pre-colombian period, which were about $25 \%$ to $70 \%$. It might be considered that smelting precious metals that occur naturally from alluvial deposits structured the alloys. In other times, platinum grains were retrieved to avoid retrieving silver gold. In most cases, artefacts of gold could be plated together with platinum, through hammering and welding thinner platinum sheets on gold.

\section{Contribution of Scientists}

Primitive metallurgists were traditionalists and empiricists and the absence of skills until the middle age period precluded the application of scientific knowledge of craft and art of metallurgy. In the modern age, metallurgy has been segmented into two elements, physical metallurgy and extraction metallurgy, and whereas both are considered amenable to scholastic assessment, it is in the segment of physical metallurgies that we can first witness the signs of scientific observation. Anglo Saxon and the Romans were professional when it comes to the structuring of patternwelding sword. They were familiar with the hallmarks of quality provisions and they should be aware that this 
amounted to critical forging. Theophilus had presented their observations of physical features, certainly, the malleability quality tests and were more familiar to the procedures of heat-treating steel.

However, the absence of knowledge on the present distinction of the features of wrought iron, steel and case iron acts as an inhibiting aspect to their overall professionalism. During the 17 millennium, it was fundamental for novel innovations in the field of science to be introduced. Jansen introduced compound microscopes in early 1600. Dynamists, mathematicians and astronomers had contributed significantly to the field of science but the features of material science based on experiments and observations being contingent were not considered worthwhile of rare assessments. With these expectations, Isaac Newton was interested in the physical features of metals including their places of origin and profits to be achieved from them.

\section{Metallography and Metallurgy}

Among the wide-range, scientific observations on the features of metals include the Freshman observations that led to a publication of literature on locks mitting in the late 1920s. Just like other scientists, freshman approached different subjects in metallurgy, including rolling mills for lead and machines used for file cutting, including a detailed presentation of operations for tempering and hardening. Freshman is considered the first one to associate hotter shortness in wrought irons with Sulphur smells. The scientist provided the earlier definition of cementation of minor iron pieces of iron packets with different layers that have alternating charcoal in crucible. Freshman provided a way forward on steel quenching from hotter temperatures that might consider it worthless; nonetheless, it does not considered its grain sizes.

Another key contribution to the features of metals was from Henry Power who, based on the application of microscopes, identified that a polished metallic surface was completely filled with irregularities, asperities, cavities ad fissures. In early $1770 \mathrm{~s}$, Reaumur considered following a discussion of the features of ferrous metals based on their grain structures. In addition, just like Leonardo, Reaumur was competent as a scientists in his days. He considered following reinvention of malleablising casting irons and defined the processes in his literature texts. It was considered that real inventions can be presented by Chinese sooner as starting to utilize casting irons some centuries Be.

In the $18^{\text {th }}$ millennium, various hypotheses regarding the corpuscular condition of matter were present and it was evident that they significantly influenced Reaumur. The scientists observed, using microscopes, that steel particles incorporated large grain pieces. Despite the fact that he provided the term 'molecules' to minor entities, he embraced that these were structured until minor entities that he claimed he was able to visualized. It is correct to wonder if the scientist was searching for pearlite structures or not. He was also unaware of the implications of incipient melts on the boundaries of the grains.

In addition, Reaumur was considered the first one to advocate the usage of hardness evaluation based on the application of indentation evaluation of crossing prisms with scratches hardness tests. Therefore, it was projected that Mohs in the early 1820s. For mechanical evaluation of wires, the scientist devised machines by which quenched steel wires were flexible until breakage. One of its ends was gripped in its vise and their impact of a bend was evaluated using some turn-offs of screw threads that were applicable to wire loads. These were machines of limited applications, which were presumed to gain more attention of watchmakers for evaluating the features of springs than any other scientists. However, Reaumur referred to the earlier for of dead load fracture tests whereby weights were incorporated to vertical wires.

Another contribution was from French scholars in the $18^{\text {th }}$ millennium. Their contributions were remarkable and followed that of Reaumur. One of the French scholars i.e. Desaguliers T. followed the works of modeling astronomical frameworks and the fractioning of electric machines in the early 1720s. It was thus discovered that larger lead spheres would possibly welded forcibly using twisted cleaned and flattened surfaces considered normal loads.

After that, Musschenbroek Vam followed a development that targeted at developing mechanical testing machines. Therefore, in the early 1730s, Swedenborg considered treatising irons and coppers that brought together two volumes of metallurgical methods during the late $16^{\text {th }}$ century and early $17^{\text {th }}$ century. Despite the fact that this incorporated little initial ideologies of value, the scientists' illustration on metallurgical plants and methods; however, fill the gaps in the literature works of Agricola and Biringuccio.

In general, most firms during the $18^{\text {th }}$ century were obliged to depend on primitive and presented fewer contributions to scientists' advancements. However, one of the various calibers was from Grignon, the owner of ironwork and the person who added to memoirs series printed in 1770s. Grignon was known for his enthusiasm in metallurgy. He was the first scientists to present accurate description of the transformations in blast fires and burden during their descending in the furnaces. The scientist noted that gases were evolved during the process of casting and led to ignition in the moulds. In case the moulds were considerably impermeable, there were explosions, which are evident; and casting would be porous to provide essential satisfactions.

Grignon presented an observation of the creation of kish graohite on surfaces of cast irons. However, the scientist assumed that is comprised of attenuated cast irons. Its creation happened with the ratio of ores and fuels were grater and the same proportion of blasts. In this case, irons were left longer in hearths and its existence was considered wasteful. Grignon's definition of wrought irons was a massive fibre bundle that is separate from each other using vitrified matters. Grignon's detailed descriptions indicate dendrite masses of polygonal crystal of significant precision. The scientist regarding his fires as a tool whereby art considerably approached the aspect of nature in copying igneous products and evaluating full-sized blast fires and cooling it for about 20 days to retrieve larger slag and metal crystals.

Bergman Torbern shed light on the available variations between steel and irons. Torbern's major contribution to the field of metallurgy was identified in Dissertatio-Chemica-Deanlysiferri documented in the early 1780s. During this period, chemists in Sweden were the leaders in the globe when it comes to the development of novel analytical 
methods. Oxygen has been considered and Bergman vividly comprehended its obligations in the combustion; however, he continued to utilize earlier phlogiston theories to illustrate his findings on irons. During the same period, Svenkinman, more enthusiastic in welding gun barrels, has proved that steel incorporated something more to irons in copper introduced in the early 1770 s. Svenkinman identified that, whereas pure Osmond irons lost about $86 \%$ of its acid weight, the same weights of steel after similar treatment lost about $29 \%$ and was incorporated in dark ash grey films.

Nonetheless, Svenkinman did not identify the films. Bergman dissolved different $\mathrm{Fe}$ materials in acids and evaluated their dissolutions rates and the gas evolved from them i.e. Hydrogen. Svenkinman regarding Fe as incorporating something he referred to as phlogiston that was provided through the attacks of acids and dissolved into a more flammable air. Cast irons generated the least gasses, wrought irons generated between 48in and 50ln and steel was considered transitional with approximately 45in to 49in. Svenkinman was considerably uncertain as to if his phlogiston originated from iron or a number of impurities, which were more able to provide phlogiston compared to irons.

Svenkinman confirmed these findings by what is presently referred to as dry assay and fusion in sealed crucible, whereby ores of irons were reduced with carbons in cast irons to general slag and metal. Svenkinman found, for instance, wherever he fused $199 \mathrm{lb}$ of cast irons with approximately $49 \mathrm{lb}$ of dark hematite, which he accessed regulus with a weight of $2012 \mathrm{lb}$ with darker slag. Metallic blob beneath could be flattened under hammer to diameters of 12.5 $\mathrm{mm}$ indicating that carbons in cast irons had minimized a number of ores. Bergman did analysis based on more than 250 experiments on dry and wet assaying and considered that ductile irons incorporated about minimal carbon (plumbogo) whereas steel had lesser amounts. Cast irons were considered more saturated with it.

Bergman did the experiments and presented effective proposals and appreciations of thermochemistry principles. However, Bergman's experiments were considerably crude to provide fundamental results in the sphere. Whenever Bergman gathered the residues out of wetter assays, it was noted that the ones from cast irons had graphite and plumbaho experiments. When this is considered in form of percentage, they indicated that cast irons has about $5 \% \mathrm{C}$ whereas steel has 0.5 , whereas wrought irons had $0.15 \%$.

Bergman assessed the available variations between different residues; with some of them incorporating slag while others has phosphorus and Sulphur. Bergman was not capable of evaluating these. Other than plumbago, Bergman's other evaluations incorporate silieum, manganese and insoluble elements of slag. Siliceum amounts in steel and wrought irons are significantly lower compared to silicon contents of metals themselves, which could be neglected. If precise, this indicates that irons should have been significantly wrought and slag effectively removed.

\section{Magnetism}

Magnet's attractive power, from irons or magnetite, was introduced by Green Philosopher in the $6^{\text {th }}$ century BC, and this scientific contribution was illustrated by Lucretius in the $1^{\text {st }}$ century Be. Chinese texts reflected from the times between the $3^{\text {rd }}$ century $\mathrm{Be}$ and the $6^{\text {th }}$ century $\mathrm{AD}$, incorporate various references to the influence of the magnetite (loadstone) on irons and quantitative evaluations were done on the $5^{\text {th }}$ century AD. Magnetism application regarding compass, i.e., realization of earthwork, represents a magnet, and this is obscure. Ptolemy evaluates the islands, which were capable of attracting ships using iron nails. Whereas the attractions were acknowledged, the ideology of magnetic repulsions of poles, although identifies by primitive scholars and analysts such as Pliny, were challenging to understand.

The first illustration of magnetic compasses was indubitably Chinese. In 1088, a needle, which is magnetized through rubbing with magnetite was suspended on a threat suspended using silk. In addition, the ideology of declination, which signifies to the failure of magnetic needles to possibly align itself in an accurate manner along the north-south longitude was identified during this period. Nonetheless, thermoremanence and water compass i.e. the heated iron cooled with axis on the north-south directions translating to the north south seeking, was identified in 1044 AD. Declination was considered to be $15^{\circ}$ towards the eastern side of China.

\section{Radioactivity}

One of the major and significant discoveries in the field of metallurgy and material science in general was radioactivity. Becquerel, in 1896, introduced the concept and induced it following x-ray emanation, which introduced by Rontgen four years prior. Rontgen has obtained x-rays using the bombardment of metallic targets with high-energy electrons. Some of the metals used by Becquerel were capable of transmitting radiations, which were the same as those from $\mathrm{x}-$ rays. This was proven by incorporating metallic components on the photographic plate that has been enclosed in dark paper and stored for a week.

Becquerel notices that some of the placed were darkness as if they had been exposed in an x-ray. In these instances, he noted that the elements included thorium or uranium, and all of these metals were considered to have higher atomic weights. In 1898, Pierre Curries and Marie Currie identified that a single example of the ore identified from pitchblende emitted more energy compared to thorium or uranium elements.

In the next few centuries, this reduction would be approximately $4.5 \%$ out of $95.5 \%$ that remains. In case one plots an emission rate e.g. darkening degree of photographic plates in a particular timeframe over lapse duration, it is possible to get a smoother curve of an exponential form. An emission rate from various radioactive components is different and to make potential comparisons, it is applicable to discuss about half-life or the overall duration, which might elapse before the general level of emissions diminishes to a single half-life of its initial. Parameter value for radium is approximately 1500 years; however, that for thorium or uranium is longer i.e. millions of years. 


\section{CONCLUSION}

In conclusion, this paper has evaluated the history of metallurgy dating from the Neolithic period. This research narrows down to a discussion of three metals i.e. iron, copper and gold. Therefore, this paper proceeds with an analysis of the fundamental contributions of scientists and chemists of lithic people. When focusing on the advent of metallurgy, it is fundamental to reflect on particular methods in daily application according to lithic communities, because the application of metals was known out of lithic societies. For instance, the application of red oxides of irons in funerary and ritual practices is known in most parts of the world according to lithic people. There is less doubts that during the Neolithic pottery phase, greener minerals were utilized in the decoration of pots, and their instabilities would be discovered sooner; unlike red oxide of irons. However, there are certain discoveries that have not been certified scientifically to date. For instance, the impact of the reduction state of generating globules of metallic lead in the process of lead glaze firing leaves the modern society wondering if the process of smelting was achieved this way. To date, there are no evidences for this. However, the ideology that kilus, whereby reducing states would be applicable, were not identified until the Copper Age, which means that such accidents blamed for the introduction of smelting.

\section{References}

[1]. Y. Shibuta, M. Ohno and T. Takaki, "Computational Metallurgy: Advent of Cross-Scale Modeling: High-Performance Computing of Solidification and Grain Growth (Adv. Theory Simul. 9/2018)", Advanced Theory and Simulations, vol. 1, no. 9, p. 1870020, 2018. Available: 10.1002/adts.201870020.

[2]. S. Park, "Aspect and Meaning on the Red Painted Pottery in Korean Peninsula during the Neolithic period", Korea Neolithic Research Society, no. 37, pp. 1-39, 2019. Available: 10.35186/jkns.2019.37.1.

[3]. G. Artioli, I. Angelini, G. Kaufmann, C. Canovaro, G. Dal Sasso and I. Villa, "Correction: Long-distance connections in the Copper Age: New evidence from the Alpine Iceman's copper axe", PLOS ONE, vol. 12, no. 12, p. e0189561, 2017. Available: 10.1371/journal.pone.0189561.

[4]. E. Miller, P. Ku, J. Hitchcock and W. Magee, "Availability of Zinc from Metallic Zinc Dust for Young Swine", Journal of Animal Science, vol. 52, no. 2, pp. 312-315, 1981. Available: 10.2527/jas1981.522312x.

[5]. S. Grecian, S. Adam and A. Syed, "From the bronze age to the iron age", Endocrine Abstracts, 2015. Available: 10.1530/endoabs.38.p241.

[6]. V. Nikulkina, A. Rodin and B. Bokshtein, "Diffusion of tin in copper-tin system solid solution", Izvestiya Vuzov. Tsvetnaya Metallurgiya (Universities' Proceedings Non-Ferrous Metallurgy), no. 2, pp. 32-38, 2020. Available: 10.17073/0021-3438-2020-2-32-38.

[7]. C. Fuller, "The loss of copper and nickel during pre-atomization heating periods in flameless atomic absorption determinations", Analytica Chimica Acta, vol. 62, no. 2, pp. 442-445, 1972. Available: 10.1016/0003-2670(72)80055-2.

[8]. J. Baron, M. Maciejewski, B. Miazga, K. Nowak and D. Sych, "More Bronze Age less bronze: copper axes in the late Bronze Age hoard from Karmin, Poland", Antiquity, vol. 94, no. 377, 2020. Available: 10.15184/aqy.2020.139.

[9]. G. ALBERTI, "Issues in the absolute chronology of the Early-Middle Bronze Age transition in Sicily and southern Italy: a Bayesian radiocarbon view", Journal of Quaternary Science, vol. 28, no. 6, pp. 630-640, 2013. Available: 10.1002/jqs.2659.

[10]. L. Márton, J. Talpas and E. Bitay, "Issues of The Usability of Copper Ore (Chalcopyrite) From Bălan for Ustensiles Production in The Bronze Age", Müszaki Tudományos Közlemények, vol. 8, no. 1, pp. 67-74, 2018. Available: 10.33894/mtk-2018.08.08.

[11]. M. Holzer, M. Frants and B. Pasquier, "The age of iron and iron source attribution in the ocean", Global Biogeochemical Cycles, vol. 30, no. 10, pp. 1454-1474, 2016. Available: 10.1002/2016gb005418.

[12]. A. Roula and G. Kosnikov, "Manganese distribution and effect on graphite shape in advanced cast irons", Materials Letters, vol. 62, no. 23, pp. 3796-3799, 2008. Available: 10.1016/j.matlet.2008.04.056.

[13]. J. Pandey and B. Prasad, "Sliding Wear Response of a Leaded-Tin Bronze: Influence of the Counterface Material Characteristics", Journal of Materials Engineering and Performance, vol. 7, no. 1, pp. 122-129, 1998. Available: 10.1361/105994998770348142.

[14]. V. Bird and H. Hodges, "A Metallurgical Examination of Two Early Iron Swords from Luristan", Studies in Conservation, vol. 13, no. 4, p. 215, 1968. Available: $10.2307 / 1505431$.

[15]. T. R., "The Sampling and Assay of the Precious Metals: comprising Gold, Silver, Platinum, and the Platinum Group Metals in Ores, Bullion, and Products", Nature, vol. 93, no. 2320, pp. 157-158, 1914. Available: 10.1038/093157b0. 